\title{
Comparison between the complications of cataract surgery following local anaesthesia with short stay and general anaesthesia with a five-day hospitalisation
}

\author{
STEPHEN A VERNON AND HUNG CHENG \\ From the Oxford Eye Hospital, Walton Street, Oxford OX2 $6 A N$
}

\begin{abstract}
SUMMARY In December 197997 patients underwent intracapsular cataract extraction under local anaesthetic with planned discharge on the day after operation. Twenty-three of these patients had a prolonged stay in hospital, and five of these required early operative intervention following surgical complications. Sixteen patients did not attain a visual acuity better than $6 / 18$. The visual outcome and postoperative course are compared with those of a similar group of patients who stayed in hospital for five days after intracapsular cataract extraction.
\end{abstract}

During the summer of 1979 waiting lists for cataract surgery at the Oxford Eye Hospital steadily lengthened. In response 97 patients underwent intracapsular cataract extraction under local anaesthesia in a nine-day 'cataract drive.' Patients were selected carefully from the waiting lists after attending a screening clinic where they were examined by a senior registrar and interviewed by a social worker experienced in visual rehabilitation. This was to assess their suitability for surgery under local anaesthesia and to plan provisions for a return to the community on the day following surgery.

The aim of this retrospective study is to assess the results of this short-stay surgery in terms of the visual outcome and the complications arising as a result of the surgery combined with early discharge from hospital.

The results of the cataract drive are compared with those of a similar series of patients who had intracapsular surgery under general anaesthesia with a five-day postoperative stay in hospital. This group of patients are taken consecutively from an on-going 'cataract management study' and will be referred to as CMS patients.

\section{Materials and methods}

Patients considered suitable for the cataract drive at the screening clinic were given a date for admission to hospital between 2 and 12 December 1979. The

Correspondence to Mr S A Vernon, FRCS. operation was performed on the day following admission, patients being prepared for theatre in the routine manner practised in Oxford. All surgery was performed by surgeons of consultant or senior registrar status with a senior house officer or registrar as assistant. Retrobulbar and facial anaesthesia was employed in all cases, the choice of agent being left to the surgeon. All extractions were planned intracapsular and were performed with the cryoprobe with the use of Zonulysin (chymotrypsin) at the surgeon's discretion. Limbal wounds were sutured with $8 / 0$ virgin silk and antibiotic drops or ointment applied before padding the eye.

First dressings were performed on the morning after operation by the surgeon, all eyes being examined at the bedside. If the cornea was not seen to be clear, the patients were also examined at the slit-lamp, where the intraocular pressure was measured with the Goldmann tonometer.

Patients were discharged home or to prearranged convalescence on the first postoperative day with a mydriatic and steroid/antibiotic drops, unless discharge was considered unwise by the surgeon. (A small hyphaema or a moderate rise in intraocular pressure to less than $30 \mathrm{mmHg}$ was not considered reason enough to delay discharge.)

Patients were assessed in the outpatient clinic on the fourth postoperative day and refraction was performed six weeks later for spectacles.

Patients on the CMS had similar surgery under general anaesthesia with the use of $10 / 0$ monofilament nylon sutures in place of $8 / 0$ virgin silk. 
Gentamicin $20 \mathrm{mg}$ was given subconjunctivally in place of the antibiotic drops or ointment at the close of surgery and all patients were discharged on the fifth postoperative day.

All material used for this study was obtained by the first author from scrutiny of patients' notes four years after surgery for the cataract drive and between two and four years for the CMS patients.

\section{Results}

Table 1 shows the numbers of patients in each group by age, and Table 2 shows the last recorded corrected visual acuity. Follow-up in both groups ranged from 2 to 48 months, with a mean of 19.5 months for the cataract drive and 26 months for the CMS patients. Table 3 shows the causes of decreased acuity in the eyes whose last recorded acuity was $<6 / 18$ in each group. Table 4 indicates the range of postoperative astigmatism at the six-week refraction in the two groups.

Table 5 records the surgical complications for the two groups. Of the six cases in the cataract drive with vitreous loss at surgery, chymotrypsin was used in all but one case; it was used in all the cases which suffered vitreous loss in the CMS group.

Nineteen cataract drive patients stayed in hospital

Table 1 Age distribution of patients

\begin{tabular}{lcc}
\hline Age & Cataract drive & CMS \\
\hline $45-49$ & 1 & 0 \\
$50-54$ & 5 & 1 \\
$55-59$ & 7 & 6 \\
$60-64$ & 10 & 9 \\
$65-69$ & 17 & 21 \\
$70-74$ & 19 & 26 \\
$75-79$ & 18 & 20 \\
$80-84$ & 12 & 11 \\
$85-89$ & 6 & 3 \\
$90-94$ & 2 & 0 \\
Total & 97 & 97 \\
\hline
\end{tabular}

Table 2 Visual acuity at last follow-up visit

\begin{tabular}{llc}
\hline Acuity & Cataract drive & CMS \\
\hline $6 / 4-6 / 6$ & 50 & 51 \\
$6 / 9$ & 17 & 34 \\
$6 / 12$ & 10 & 6 \\
$6 / 18$ & 6 & 3 \\
$6 / 24$ & 4 & 1 \\
$6 / 36$ & 3 & 1 \\
$6 / 60$ & 1 & 0 \\
Counting fingers & 0 & 0 \\
Hand movements & 2 & 1 \\
Not recorded & 4 & 0 \\
Total & 97 & 97 \\
\hline
\end{tabular}

longer than planned. Sixteen of these prolonged stays were due to unforeseen surgical complications (see Table 5). The other three reasons for delayed discharges were recorded as 'patient unwell,' 'patient's age,' and 'ocular pain requiring analgesia.' Four patients were readmitted with severe complications at the outpatient visit on the fourth postoperative day, making a total of 23 cataract drive patients who had an unplanned prolonged stay in hospital. Five of these had to return to the operating theatre for further surgery (two wound leaks resutured, one iris prolapse rectified, one anterior vitrectomy for pupil block glaucoma, and one vitrectomy for endophthalmitis). Of these five patients three were under the age of $65(0.01<p<0.001)$. None of the $97 \mathrm{CMS}$ patients required further surgery in the immediate postoperative period $(0.05<\mathrm{p}<0.02)$.

\section{Discussion}

The two groups of patients reviewed were similar in age and were both selected because of the absence of other ocular pathology. Both groups had surgery performed by consultants and senior registrars skilled in a standard operation. The two major

Table 3 Cause for a final acuity of $<6 / 18$

\begin{tabular}{|c|c|c|}
\hline & Cataract drive & $C M S$ \\
\hline \multicolumn{3}{|l|}{ Surgical } \\
\hline Cystoid macular oedema & $\begin{array}{l}2 \text { (vitreous } \\
\text { loss) }\end{array}$ & $\begin{array}{l}3 \text { (no } \\
\quad \text { vitreous loss) }\end{array}$ \\
\hline \multicolumn{3}{|l|}{ Corneal decompensation } \\
\hline following capsule rupture & 1 & 0 \\
\hline Pupil block glaucoma & 1 & $\mathbf{0}$ \\
\hline Capsule remnants & $\mathbf{0}$ & 1 \\
\hline \multicolumn{3}{|l|}{ Non-surgical } \\
\hline Senile macular disease & 4 & 1 \\
\hline Myopic retinal degeneration & 2 & $\mathbf{0}$ \\
\hline Diabetic maculopathy & 2 & $\mathbf{0}$ \\
\hline \multicolumn{3}{|l|}{ Chronic simple glaucoma (known } \\
\hline to exist prior to surgery) & 2 & $\mathbf{0}$ \\
\hline Macular hole & 1 & $\mathbf{0}$ \\
\hline Tobacco/alcohol amblyopia & 0 & 1 \\
\hline No cause recorded in notes & 1 & 0 \\
\hline Total & 16 & 6 \\
\hline
\end{tabular}

Table 4 Postoperative astigmatism at six weeks

\begin{tabular}{lcc}
\hline Astigmatism in dioptres & Cataract drive & CMS \\
\hline $0-1 \cdot 00$ & 30 & 52 \\
$1 \cdot 25-2 \cdot 00$ & 36 & 33 \\
$2 \cdot 25-3 \cdot 00$ & 14 & 11 \\
$3 \cdot 25-4 \cdot 00$ & 7 & 1 \\
$4 \cdot 25-5 \cdot 00$ & 4 & 0 \\
Not recorded & 6 & 0 \\
Total & 97 & 97 \\
\hline
\end{tabular}


Table 5 Surgical complications

\begin{tabular}{lll}
\hline & $\begin{array}{l}\text { Cataract } \\
\text { drive }\end{array}$ & CMS \\
& & \\
\hline $\begin{array}{l}\text { Intraoperative } \\
\text { Capsule rupture }\end{array}$ & 6 & 6 \\
Vitreous loss & 6 & 4 \\
Apparent at first dressing & $11(8)^{*}$ & 9 \\
IOP 25 mmHg & $22(4)$ & 8 \\
Macroscopic hyphaema & $1(1)$ & 0 \\
Iris prolapse & $2(2)$ & 0 \\
Flat anterior chamber from wound leakage & $1(1)$ & 0 \\
Severe uveitis & & \\
Occurred between 2nd and 4th & & \\
postoperative days & $1(1)$ & 0 \\
Pupil block glaucoma & $1(1)$ & 1 \\
Endophthalmitis & $1(1)$ & 0 \\
Total hyphaema & $1(1)$ & 0 \\
Subconjunctival abscess & & \\
Occurred much later & 2 & 1 \\
Retinal detachment & 0 & 1 \\
Updrawn pupil & $55(20)$ & 30 \\
Total & & \\
\hline & &
\end{tabular}

(Numbers in brackets indicate cases with prolonged hospitalisation.)

variables were the use of local anaesthesia in one group compared with general anaesthesia in the other and the difference in duration of stay in hospital.

There were more patients in the CMS group with better postoperative acuity (Table 2), but this could be accounted for by the fact that in that group visual acuity was a point of observation in a prospective study, and the best corrected acuity was always obtained at each visit. The performance of an operation is not expected to be different whatever the duration of stay in hospital, and it is as expected that the intraoperative complications were similar for the two groups (Table 5). The greater number of complications on the first postoperative day in the cataract drive patients is not explained but is not significant except for macroscopic hyphaema.

Interestingly, 9 and $11 \%$ of cases in the two groups respectively had a raised intraocular pressure to $>25$ $\mathrm{mmHg}$, and there was a strong correlation with the use of chymotrypsin. The IOP exceeded this level in 20 of 113 cases in which it was used compared with 1 of 81 cases when it was not $(p<0.001)$. In 8 of 11 patients in the cataract drive group the pressure was considered too high for safe discharge from hospital at the first postoperative day. Chymotrypsin should probably not be used routinely if early discharge is intended.

It has been argued' that there is no benefit from admission to hospital for cataract surgery in terms of patient satisfaction or the prevention of surgical complications. Only a randomised control trial will provide an answer to these contentions.
Altogether 20 of 97 patients in the short stay group were detained beyond the first postoperative day because of various complications or untoward events. That five cases required additional surgery in this group, of which three were under 65 years old, while none required it in the CMS group, is interesting. No definite conclusions as to the reason(s) for this difference can be made from a retrospective study such as this, but possibly the use of local anaesthesia for cataract extraction in patients under 65 leads to greater complications.

A major concern of short stay or day case surgery is the fear that treatable complications may not be detected quickly, and it is worrying that serious complications developed in four cases (Table 5) in the cataract drive group between the second and fourth postoperative day. This raises the question of how frequently patients should be seen after day case surgery; for, if they must be seen daily for a few days, difficulties will arise if they live outside certain limits. In the case of endophthalmitis it is commonly detected between 18 and 72 hours postoperatively, ${ }^{2}$ and early intervention is essential for a successful outcome. ${ }^{34}$ The one case in the CMS group was detected on the third postoperative day, and 6/9 vision was regained after prompt treatment.

For the cataract drive group $23.7 \%$ of patients stayed in hospital longer than was originally intended or required readmission. The criteria for readmission may become more clearly defined if day care surgery becomes commonplace, but beds must still be made available for such contingencies, and provision must therefore be made in planning and bed allocation.

If day case cataract surgery is contemplated on elderly patients, there may not be the strong social or financial incentive, as exists in some parts of the world, for patients or relatives to cope with the problems. Further, it is questionable whether patients should be discharged on the same day as they have general anaesthesia, particularly if they live alone. A further point to consider is the increasing use of intraocular implants, for which the use of general anaesthesia is even more prevalent. A discussion on intraocular lenses is outside the scope of this paper, but some principles of patient management are similar for all types of cataract surgery. It is unlikely, therefore, that day case cataract surgery will at present be suitable for all patients in Great Britain. The major difference between day case and short stay surgery is that, in the latter, the surgeon retains the option to discharge the patient and is in a position to recognise complications and detain those likely to need further treatment. Our study suggests that complications are likely to occur in the first few days postoperatively.

The aim of any surgical treatment must be to 
obtain the best result with the minimum of complications at the least inconvenience to the patient. To achieve this aim in cataract surgery requires early detection of treatable complications by means of routine monitoring during the early postoperative period, with facilities to detain or readmit for further treatment if necessary.

We acknowledge the help of Mr D Boase and Dr C Buckley, who planned and organised the cataract drive.

\section{References}

1 Ingram RM, Banerjec D, Traynar MJ, Thompson RK. Day-casc cataract surgery. BrJ Ophthalmol 1983; 67: 278-81.

2 Peyman GA. The lens, cataract and its management. In: Peyman GA, Saunders DR, Goldberg MF, eds. Principles and practice of ophthalmology. Philadelphia: Saunders, 1980; 1: 599.

3 Jaffe NS. Cataract surgery and its complications. 2nd ed. St Louis: Mosby, 1976: 63.

4 Peyman GA, Raichand M, Bennett TO. Management of endophthalmitis with pars plana vitrectomy. BrJ Ophthalmol 1980; 64: 472-5. 